\title{
Female Genital Mutilation: A Violation of the Human Rights of Girls and Women a Call for Concrete Policies and Renewed Actions
}

\section{Kaliyaperumal Karunamoorthi*}

\section{Department of Environmental Health Science\& Technology, College of Public Health and Medical Sciences, Jimma University, Ethiopia}

\section{Introduction}

Female genital mutilation, also known as 'female genital cutting' or 'female circumcision', refers to "all procedures involving partial or total removal of the external female genitalia or other injury to the female genital organs whether for cultural, religious or other non-therapeutic reasons" [1]. Despite more than 25 years of efforts to curtail the practice of Female Genital Mutilation/Cutting (FGM/C), it still remains as a deeply rooted tradition in more than 29 countries of Africa and in some countries of Asia and the Middle East [2]. It has been widely practiced among certain immigrant communities in North America and Europe too [1]. It has been estimated that nearly 30 million girls are at the risk every year [2]. The FMG/C is mostly performed for the girls below 15 years of age. The main objective of this editorial is to generate the awareness and understanding on FGM/C as a human right and public health concern and this communication can serve as a base-line for the design and implementation of appropriate policies and programmes, to eliminate this harmful practice in the future and make the world safer for women and girls.

\section{Historical Perspectives}

Where and when the practice was first originated is not clearly known. The existing evidence suggests a form of female circumcision in Egyptian mummies nearly 5000 years ago [3]. In ancient Rome, metal rings were passed through the labia minora of women slaves to prevent procreating. It also had been practised in Britain, Canada and the USA in the 18th century to prevent masturbation, and to cure hysteria and some other psychiatric conditions [4]. In the United Kingdom, around 19th century surgical removal of the clitoris was an accepted technique for the management of epilepsy, sterility and masturbation [5]. In Africa and the Middle East, FGM/C is thought to have taken root from untold centuries ago [6].

\section{Reasons for FGM/C}

Indeed the mothers and other family members are aware that FGM/C can bring various physical and psychological difficulties to their girl children. However, they consider it as a proper way to raise and protect their daughters for adulthood as well as marriage. The people believe that FMG/C is a social obligation to avoid shame and social exclusion from their ethnic group and society. It is an act of selfenforcing social convention [7]. The mental map shows some of the compounding factors inter-linked to the continuation of this practice in the society (Figure 1) (PATH/WHO, 1999) [8].

\section{Prevalence of FGM/C}

Though FGM/C is very common in the 29 African and Middle East countries, it is only now that reliable prevalence data are available (Figures 2,3) [2]. It shows that currently over 125 million girls and women have undergone FGM/C (Figures 2,3) [2], and nearly 3 million girls are at the risk of undergoing FGM/C every year [1]. It has been estimated that about 91.5 million girls and women above 9 years of age are living with the consequences of female genital mutilation in Africa [9].
Most of the women who have experienced FGM/C live in one of the listed 29 countries, while nearly half of them live in just two countries viz. Egypt and Ethiopia (Figure 2). The recent survey data indicates the prevalence of $\mathrm{FGM} / \mathrm{C}$ to range from $5 \%$ to $97 \%$ among the female population $[10,11]$. The prevalence has also been reported among some communities on the Red Sea coast of Yemen, Jordan, Oman, the Palestinian Territories (Gaza), Saudi Arabia and in certain Kurdish communities of Iraq too. It is also reported among certain groups in India, Indonesia and Malaysia [2,6]. Besides, this practice is widespread among immigrant communities of Europe, Australia, New Zealand, Canada and the United States of America [12].

\section{Female Genital Mutilation/Cutting: An Overview}

The age at which girls undergo FGM/C varies according to the culture, country and ethnic group practising it. It may be performed among the newborn girls, during childhood, adolescence, at the time of marriage or during the first pregnancy (Table 1). In some cultures, where FGM/C is an accepted norm, a woman is reinfibulated (restitched) following childbirth. About $80 \%$ of the cases of FGM/C involve excision of the clitoris and the labia minora[12]. The more extreme type of FGM, infibulation, comprises around $15 \%$ of all procedures. The highest rates for infibulations are found in Djibouti, Somalia and northern Sudan[13].

FGM/C is usually performed by an elderly woman of the village or by the village barbers or by the traditional midwives (Table 1) [14]. In most cases, a blade, knives or razor is used as a tool for cutting in Egypt, and one in four daughters has been observed to have undergone the procedure without an anaesthetic of any kind [2]. In some countries, more affluent families seek the medical personnel to perform the FGM/C in order to avoid the risks as results of unskilled operations and unhygienic conditions. However, the "medicalization" of FGM/C - which is a willful damage to healthy organs for non-therapeutic reasons - is unethical and has been consistently condemned by the World Health Organization $[15,16]$. The specific impact of FGM/C on the health of a girl or woman largely depends upon certain interlinked vital factors viz.the extent and type of the mutilation, the skill of the operator, the cleanliness of the tools and setting, and the physical condition of the girl or woman $[6,14]$.

*Corresponding author: Kaliyaperumal Karunamoorthi, Unit of Medical Entomology and Vector Control, Department of Environmental Health Science\& Technology, College of Public Health and Medical Sciences, Jimma University, Jimma, Ethiopia, Tel: +251-913-547-847; E-mail: karunamoorthi@gmail.com

Received December 09, 2013; Accepted December 11, 2013; Published December 16, 2013

Citation: Karunamoorthi K (2013) Female Genital Mutilation: A Violation of the Human Rights of Girls and Women a Call for Concrete Policies and Renewed Actions. J Socialomics 3: e121. doi:10.4172/2167-0358.1000e121

Copyright: (c) 2013 Karunamoorthi K. This is an open-access article distributed under the terms of the Creative Commons Attribution License, which permits unrestricted use, distribution, and reproduction in any medium, provided the original author and source are credited. 


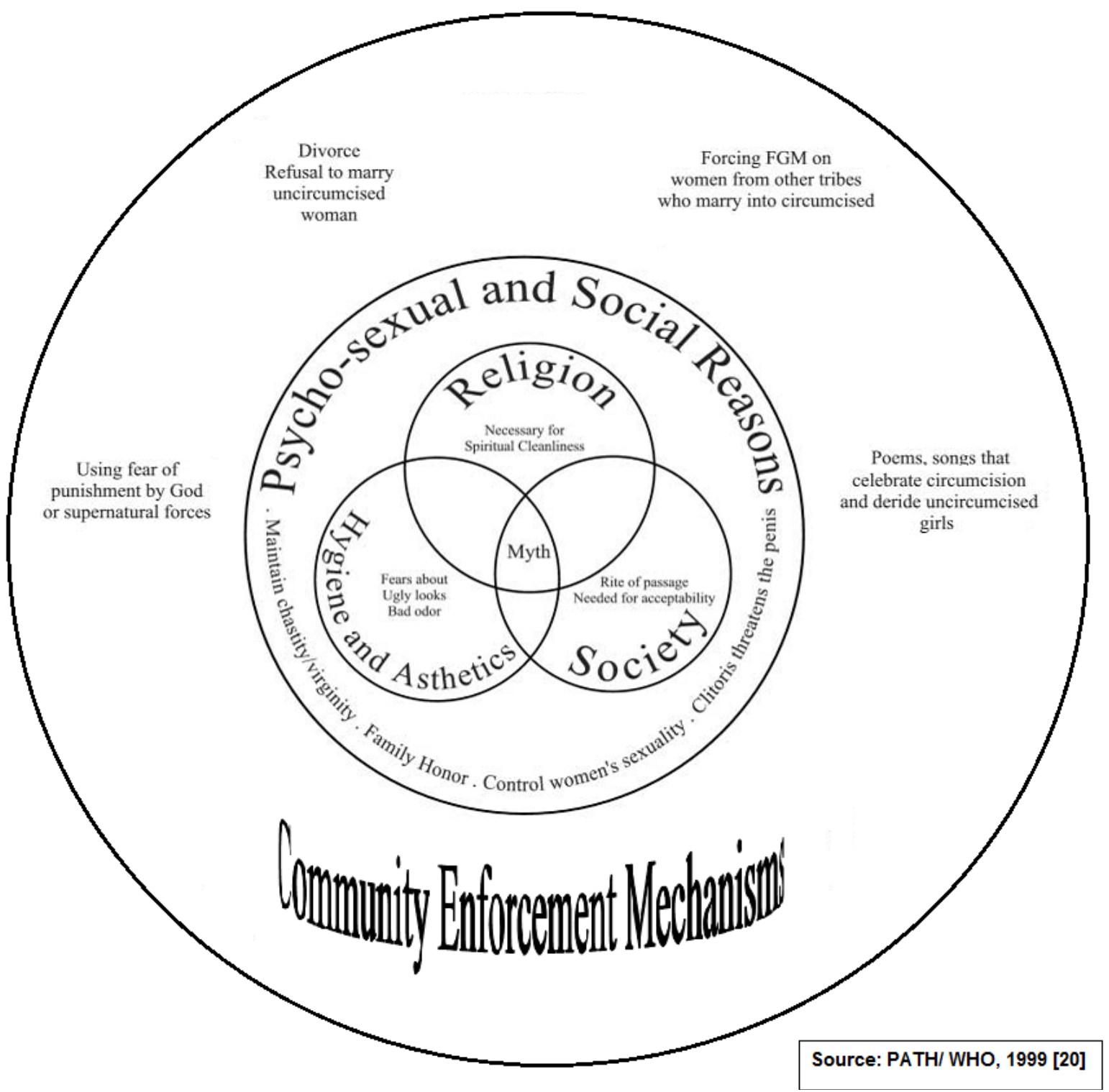

Figure 1: The Mental map shows the compounding factors for the continuation of FGM/C practice.

\section{Types of FMG/C}

Indeed FGM/C covers a wide-range of procedures, but in the great majority of cases it involves the excision of the clitoris and the labia minora. At its most extreme, the procedure entails the excision of almost all the external genitalia and the stitching up of the vulva to leave only a tiny opening. Whatever form it takes, FGM/C is a violation of the human rights of girls and women and it is a grave threat to their health [16]. The WHO (1997) [15] classifies FGM/C (Table 2) into four types as follow:

\section{Negative public health impact}

FGM/C has no known health benefits. On the contrary, it is multidimensional and affects the physical and mental health of girls and women in many ways. The removal of or damage to healthy, genital tissue interferes with the normal functioning of the body and causes several short and long-term negative health consequences [1].
Severe pain and bleeding are the most common of all forms of FGM/C. Since in most cases the procedure is carried out without anaesthesia, the resulting pain and trauma can produce a state of clinical shock [6]. Immediate complications include delayed or incomplete healing, and infections $[1,17]$.

Long-term consequences are more difficult to attribute, but may include damage to adjacent organs, sterility, anaemia, recurring urinary tract infections, the formation of dermoid cysts and even death [18]. Birth complications may also arise, leading to increased need for Caesarean sections and excessive bleeding during delivery [2]. It has been reported that babies born to women who have undergone female genital mutilation suffer a higher rate of neonatal death compared with babies born to women who have not undergone the procedure [1] FGM is estimated to lead to an extra one to two perinatal deaths per 100 deliveries [14]. Today, it is also scientifically proven that FGM/C is harmful to both women and their babies. 
Citation: Karunamoorthi K (2013) Female Genital Mutilation: A Violation of the Human Rights of Girls and Women a Call for Concrete Policies and Renewed Actions. J Socialomics 3: e121. doi:10.4172/2167-0358.1000e121

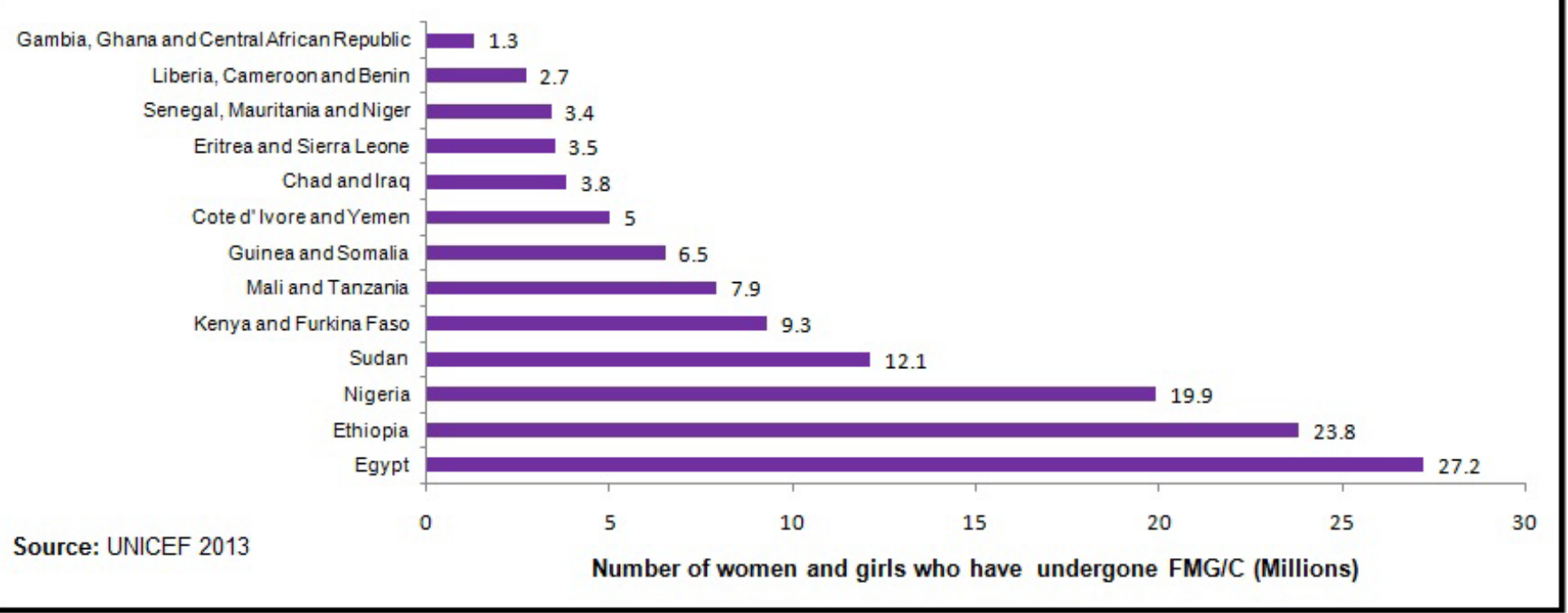

Figure 2: List of countries where number of women and girls has undergone FGM/C in millions.

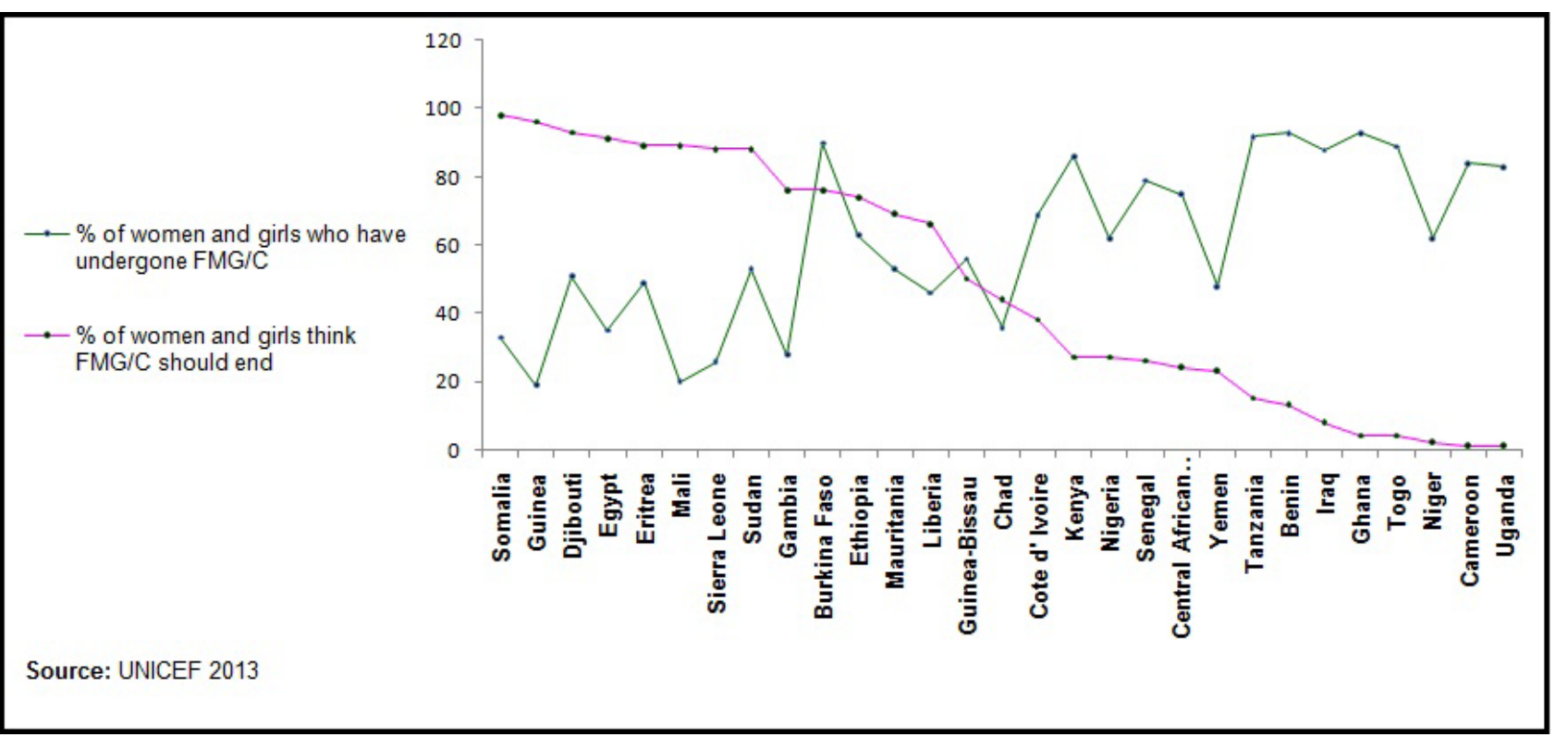

Figure 3: List of countries, the percentage of women and girls undergone FMG/C and the percentage of women and girls consider this as a harmful practice and wishing it to end.

It limits girls' schooling and their capacity to achieve their goals. It also increases the risk of becoming infected with HIV. Furthermore, it is a development as well as a governance issue. Therefore, ending all forms of FGM/C is extremely inevitable to achieve/attain the Millennium Development Goals (MDGs), especially those related to gender equality, universal primary education, maternal health, child mortality and HIV/AIDS. Fundamentally the FGM/C practice is not only a public health issue but also a violation of the basic human rights, and more specifically of fundamental child rights, and needs to be dealt with, in ways that address its underlying causes [7].

\section{Female genital mutilation/cutting:A violation of the human rights}

Internationally, there is a shift from thinking about female genital mutilation as primarily a health issue to considering it as an issue of women's health and human rights. The 1994 Declaration and Programme of Action of the International Conference on Population and Development (ICPD) strongly advocates for gender equity and equality and directly addresses reproductive health and rights issues. It specifically mentions female genital mutilation and calls for its prohibition [19]. The Declaration and Platform for Action of the 


\begin{tabular}{|c|l|}
\hline When & $\begin{array}{l}\text { In half of the countries, the majority of girls were cut before the age of } 5 . \text { Among the rest of the countries, cutting mostly occurs between } 5 \text { and } 14 \text { years of } \\
\text { age. }\end{array}$ \\
\hline How & Across a majority of countries, most daughters have had their genitalia cut, with some flesh removed. \\
\hline By Whom & In nearly all countries where FGM/C is concentrated, traditional practitioners perform the most of the procedures. \\
\hline Why & Social acceptance is the most frequently cited reason for supporting the continuation of the practice. \\
\hline
\end{tabular}

Table 1: Female Genital Mutilation/Cutting (UNICEF, 2013) [2] - An overview.

\begin{tabular}{|c|l|}
\hline Category & Descriptions \\
\hline Type I & Partial or total removal of the clitoris and/or the prepuce (clitoridectomy). \\
\hline Type II & Partial or total removal of the clitoris and the labia minora, with or without the excision of the labia majora (excision). \\
\hline Type III & $\begin{array}{l}\text { Narrowing of the vaginal orifice with the creation of a covering seal by cutting and appositioning the labia minora and/or the labia majora, with or without the } \\
\text { excision of the clitoris (infibulation). }\end{array}$ \\
\hline Type IV & All other harmful procedures to the female genitalia for non-medical purposes, for example: pricking, piercing, incising, scraping and cauterization. \\
\hline
\end{tabular}

Table 2: Classification of FGM/C.

Fourth World Conference on Women, held in Beijing in 1995, calls for an end to the FGM/C practice [20].

It is important to mention that the abandonment of FGM/C is framed not as a criticism of local culture but as a better way to attain the core positive values that underlie tradition and religion, including 'doing no harm to others'. The real efforts to end FGM/C could solve the issues like ending of violence against children and women and confronting gender inequalities [2]. Figure 2 clearly shows that many women think that this harmful practice must be ended. However, it is a very sensitive issue and must be handled very carefully as this practice is interlinked with the complex interplay of socio-cultural factors that exert pressure on mothers to preserve their tradition, which has been handed down from generation to generation [6]. Therefore, appropriate and effective interventions must be designed to convince the local communities and create a supportive society to break-down this harmful practice and the eventual eradication of this practice [8].

\section{Prevention and management strategies}

Decades of prevention efforts have contributed to a substantial reduction in the prevalence of female genital mutilation in some areas. Indeed, if the practicing communities decide themselves to abandon FGM/C, it can be eliminated very rapidly [1]. Therefore, indepth understanding on the issues with of ethnicity, custom, sociocultural and religious practices and their direct and indirect impact on the society is extremely important to identify the crucial elements. Besides innovative intervention strategies must be identified, designed and employed to the specific to the local context to convince people particularly women, girls and their family members to end this dreadful practice. The present communication is forwarding the following recommendations by considering the sensitive multi-socio-culturalracial-ethical and religious issues and spiritual concerns of this age-old practice in the new world.

\section{Proposed potential mitigation strategies}

- The FGM/C practice has been ingrained for many generations, and it requires extensive socio-cultural, ethico-legal, sexual health and clinical care awareness/education [15]. It can be achieved by bringing public awareness and creating supportive community on the harmful practice of FGM/C by broadcasting the messages of celebrities like high influential religious and political leaders,musicians, sport personnel, actors and actresses' through print and eMedia. These messages should be more specific to the local-context and culture.

- In the village level, recruiting the female volunteers, who have undergone the practice to spread the anti-FGM/C messages on the short and long-term harmful consequences to women and their babies in terms of birth complications and neonatal death. These volunteers can be trained so that they can work with other public health providers to bring out awareness to the societies through public health awareness campaigns.

- We are living in the age of social media networking and it has reached the unprecedented growth and success worldwide [21]. Consequently we must use this unique opportunity to minimize the FGM/C by devising an appropriate communication strategy to transfigure the desirable behavior change in the society [22]. It can be succeeded by means of social documentary (radio, television and social media), print media and public health awareness campaigns.

- Appropriate training programmes are required to be provided for all health and social care providers who work with the affected women and girls, and with their families [23].

- Educating the male partners and community leaders may substantially reduce the incidence of FGM/C in the future [15].

- Community-based programs must be developed to sound anti-FGM messages correcting misconceptions about the link between the clitoris and sexual drive/desire and chastity [24].

- Introducing comprehensive sex education in schools will help youth to understand the functions of the reproductive system and correct existing misconceptions about sexual desire, sexual anatomy and sexual practice and morality [24].

- Political support for eliminating the practice is important to keep the topic high on the agenda [24].Besides, taking measures to include details about the harmful practice of FGM/C and health consequences in the school curriculum could considerably reduce this practice in the FGM/C concentrated countries.

- Collaborations with governments and civil society, together with other stakeholders like healthcare professionals, traditional birth attendants, elderly women, social scientists, who engage to eliminate FGM/C worldwide, should be encouraged.

\section{Conclusion}

There is an unprecedented international and national commitment to eliminate FGM/C practice than ever before.We are all living and working in the multi-racial, multicultural communities, which afford us many opportunities to learn and appreciate various customs and traditions. However, FGM/C is a totally unacceptable and harmful 
Citation: Karunamoorthi K (2013) Female Genital Mutilation: A Violation of the Human Rights of Girls and Women a Call for Concrete Policies and Renewed Actions. J Socialomics 3: e121. doi:10.4172/2167-0358.1000e121

Page 5 of 5

traditional practice. Furthermore, it is a violation of the basic human rights of girls and women [2]. To halt this practice we must initiate grassroots campaigns by designing and mobilizing the effective antiFGM campaigns through popular media like television, internet (social networks), and mobile.

Indeed, broadcasting the anti-FGM messages/programming on television and radio in between the break of popular movies, music, drama and soap operas could increase the awareness. In addition, the empowerment of women and girls is extremely essential to break barriers and to open new doors of opportunities for the eradication of FGM/C. The suggested interventions must penetrate the gross root levels including the illiterates and those living in the remote rural areas, to curtail this age-old practice more effectively. I hope these measures could ensure millions of voiceless and unequal women' and girls' healthier lives and uphold basic human rights standards. After all, it's all our duty and responsibility for making the world safer for women/ girls in the near future.

\section{Acknowledgements}

I would like to thank Mrs. L. Melita for her sincere assistance in editing the manuscript. I sincerely would like to acknowledge my friend Mr. EmbialleMengiste who has shared his knowledge and experience on the FMG/C. Without his contributions, this editorial would have been impossible. My last but not the leas heartfelt thanks go to my colleagues of our Department of Environmental Health Science, College Public Health and Medicine, Jimma University, Jimma, Ethiopia, for their kind support and cooperation.

\section{References}

1. WHO (2008) Eliminating Female genital mutilation. An interagency statement - OHCRH, UNAIDS, UNDP, UNECA, UNESCO, UNFPA, UNHCR, UNICEF, UNIFEM, WHO.

2. United Nations Children's Fund (UNICEF) (2013) Female Genital Mutilation/ Cutting: A statistical overview and exploration of the dynamics of change. UNICEF, New York.

3. Elchalal U, Ben-Ami B, Gillis R, Brzezinski A (1997) Ritualistic female genital mutilation: current status and future outlook. ObstetGynecolSurv52: 643-651.

4. $\mathrm{Ng} \mathrm{F} \mathrm{(2000)} \mathrm{Female} \mathrm{genital} \mathrm{mutilation:} \mathrm{its} \mathrm{implications} \mathrm{for} \mathrm{reproductive} \mathrm{health} \mathrm{-}$ An overview. Br J Fam Plan 26: 47-51.

5. Kandela P (1999) Sketches from The Lancet: clitoridectomy. Lancet 353: 1453.

6. WHO (2006) Female genital mutilation - new knowledge spurs optimism. Progress in Sexual and Reproductive Health Research, World Health Organization, Geneva, Switzerland.

7. Platform for Action: Towards the Abandonment of Female Genital Mutilation/ Cutting $(\mathrm{FGM} / \mathrm{C})(2008)$ A matter of gender equality.UNICEF.
8. PATH/WHO (1999) Female genital mutilation, programmes to date: What works and what doesn't- A Review. World health Organization, Geneva, Switzerland.

9. Yoder PS, Khan S (2008)Numbers of women circumcised in Africa: The production of a total. Calverton, Macro International Inc, Maryland, USA.

10. UNICEF (2005) Female genital mutilation/cutting: a statistical exploration. New York, NY: UNICEF.

11. Innocent Research Centre (IRC) (2005) Changing a harmful social convention: female genital mutilation/cutting. Florence: UNICEF.

12. $\mathrm{WHO}(2001)$ Female Genital Mutilation. Integrating the Prevention and the Management of the Health Complications into the curricula of nursing and midwifery. A Teacher's Guide.

13. WHO (1996) Female Genital Mutilation: Report of a WHO Technical Working Group. Geneva, 17-19 July 1995. World Health Organization, Geneva, Switzerland.

14. WHO study group on female genital mutilation and obstetric Outcome (2006) Female genital mutilation and obstetric outcome: WHO collaborative prospective study in six African countries. The Lancet 367: 1835-1841.

15. World Health Organization (1997) Female genital mutilation: a joint WHO/ UNICEF/UNFPA statement, WHO: Geneva.

16. The Prevention and the Management of the Health Complications. Policy Guidelines for nurses and midwives (2001) WHO.

17. Bjälkander O, Bangura L, Leigh B, Berggren V, Bergström S, et al., (2012) Health Complications of Female Genital Mutilation in Sierra Leone. Int J Women Health 4: 321-331.

18. Mgbako C, et al., (2010) Penetrating the Silence in Sierra Leone: A blueprint for the eradication of female genital mutilation. Harvard Human Rights Journal23. $111-140$.

19. Programme of Action (1994) United Nations International Conference on Population and Development, Cairo, Egypt.

20. Beijing Platform for Action (1995) Fourth World Conference on Women, Beijing, China.

21. Karunamoorthi K (2012) Global Malaria Burden: Socialomics Implications. Journal of Socialomics.

22. Karunamoorthi K, Deboch B, Tafere $Y$ (2010) Knowledge and practice concerning malaria, insecticide-treated net (ITN) utilization and antimalarial treatment among pregnant women attending specialist antenatal clinics. J Pub Health8: 559-566.

23. Royal College of Nursing (RCN) (2006) Female genital mutilation. An RCN educational resource for nursing and midwifery staff.

24. Men's and women's perceptions of the relationship between female genital mutilation and women's sexuality in three communities in Egypt (2010) WHO. 